\title{
THE INTEGRATION OF PROBLEM SOLVING AND VALUE APPROACH: THE SHIFT TOWARD HOW TO THINK
}

\author{
Sandrita Škèrienè \\ Kaunas University of Technology, Lithuania
}

\begin{abstract}
The paper aims to reveal that values integration into problem solving fosters how to think. The first part of this paper discusses the meaning of a problem that influences the definition of problem solving. The second part discloses a structural process of problem solving and its weak points leading to rational what to think. Addressing the issues of why and how values influence decision-making that is a constituent of problem solving process, the opportunities for integration of values into problem solving are revealed. Stressing that problem solving integrating values is a significant way of future professionals learning, the framework of value-based problem solving is presented. Suggestions reveal the implementation for valuebased problem solving learning and teaching as well as directions for future research.
\end{abstract}

Keywords: values approach, problem solving, how to think, what to think, future professionals.

\section{Introduction}

The advanced processes of globalization, digital and information technology pose new challenges for education and require to master comprehensive skills, capabilities, and competencies. However, universities provide learners with systematic knowledge, practical and analytical skills (Harland, Pickering, 2010). The latter allow learners to compete in the labor market, though only for a personal economic benefits. In this way, "intelligently obedient" (Thornton, 2004, 15) future professionals are formed. As Sternberg (2017) claims that currently the focus is on highly skilled "an educational race" (p. 3). Moreover, this race "does little to choose winners who will create a positive, meaningful, and enduring difference to our future" (Sternberg, 2017, 3). The question remains to what extent we want to let that our future will depend on the decisions that are made by professionals who have been "educated" on this basis. Ironically, that, for example, education for sustainable development (e.g. Salgado, Abbott, \& Wilson, 2018) is get involved to teach certain competencies in reducing various consequences of problems solved by such professionals. 
In contrast, higher education should enable learners to get understanding of themselves, of their relationships to others, to develop an ability to make proper moral and other judgments, and to act according them (Ozoliņš, 2015, 870). Barnett (2014) argues that such higher education highlights the connections between it and the development of an individual's mind, understanding, and of the learner's entry into a form of reasoning. Reasoning that is ethical and leads to an ethical conduct (Sternberg, 2009). Everyone should take their share of responsibility and contribute to the world, society, and self-creation through conscious and wise decisions (Zsolnai, 2008; Sternberg, 2017). This places emphasis on the potential of higher education to make a valuable contribution not by shaping market participants, but by educating professionals who are responsible for itself, for the society in which they are, and for the world.

Beghetto (2016) asserts that "the spatial borders have shrunk and macrochallenges have become personalized and quite literally placed in the palms of our hands" (p. 171). Such replacement underlines the need for a new thinking which directs acting. One of the possibilities becomes problem solving identified as the way of thinking (Binkley et al., 2012), reasoning patterns as deduction, induction or even abduction (Dorst, 2011). Currently problem solving is stressed as one of the key competencies necessary for future professionals (PISA, 2015; World Economic Forum, 2016). Some researchers (Jonassen, 2011; Cho et al., 2015) suggest to incorporate it in every curriculum. While research from different disciplines deals with the development of certain problem solving abilities and/or competency (Jonassen, 1997; Ellspermann, Evans, \& Basadur, 2007; Donovan, Guss, \& Naslund, 2015; Fischer \& Neubert, 2015; Collins, Sibthorp, \& Gookin, 2016; Yener, 2016), little is known how future professionals could cope with problems, especially those that require value-based approach. Ethical issues encompassing values is more considered in decision-making (Keeney, 1994; Verplanken \& Holland, 2002; Hall \& Davis, 2007). Problem-based learning proposes to develop ethical and reflective competencies (Euler \& Kühner, 2017) as well as to recognize and to apply moral values in daily activities (Kirkman, 2017). In fact, values should be spread within education in order to help learners to discover and to understand to what and how values mean in the broader framework of things (Ozolinšs, 2015).

To address the discussed gaps, the paper aims to reveal the integration of problem solving and values. On the basis of literature review method (Grant \& Booth, 2009), this paper addresses several issues. First issue seeks to discuss the meaning of a problem and problem solving. Second, the author analyzes models for problem solving development and highlights their weak points. Third, the author explains the significance and influence of values when solving problems. For this purpose, the author designs 
the framework of value-based problem solving. Finally, the paper discusses the issues of its limitation and implementation.

\section{Trying to Grasp the Meaning of Problem Solving}

Literature that examines problem solving calls for a discussion. One of the reasons is the definition of a problem. According to Dunker (1945; as cited in Mayer \& Wittrock, 2006), a problem arises when a person has a specific purpose but does not know how to achieve it. However, this general definition represents a quite narrow view to a problem. Dostal (2015) argues that a problematic relation is not necessarily primarily based on the purpose of the person. Difficulties and internal uncertainty related to the arisen problem should also be taken into account. With reference to the classical definition, a problem is defined as the gap between the current and desired situations (Ellspermann, Evans, \& Basadur, 2007). Jonassen (1997) argues that the problem domain, problem type, the problem solving process and a solution define problems.

Contemporary research extend this discussion by presenting various types of a problem: "complex" (Fischer \& Neubert, 2015; Herde, Wustenberg, \& Greiff, 2016), "well-structured" and "ill-structured" (Basadur, Ellspermann, \& Evans, 1994; Jonassen, 1997; Ellspermann, Evans, \& Basadur, 2007), etc. Such abundance of types only confuses. As Funke, Fischer, \& Holt (2018) point out that often some of these terms lose their essence. For example, when complex and ill-structured problems share many similar features, clear borders between such terms are blurred.

Though to define the problem various terms is used, all attempts reflect the parameters of the classical problem's definition where the problem consist of the initial state, the desired end of the solution (or goal state) and paths searching for the solution (see Figure 1). Thus, the differences between the variety of the problem's types that influence their definitions could explain the first two above-mentioned parameters. Similar ideas can be found in Wood's (2006) classification of eight problem types. The data (as the initial state) and the goal determine choose of the methods for how to solve a problem as well as how to evolve the development of different capabilities. In other words, this leads to exploring a variety of paths for solving problems and focuses on the process of searching for the solution.

In view of this, problem solving seems to be a "general term" (Csapo \& Funke, 2017, 20). A wide field of research highlights the absence of consensus in the theoretical understanding of what problem solving is. However, Csapo \& Funke (2017) claim that such forms of problem solving like domain-specific and domain-general as well as analytic and complex, are well defined. Despite some differences, there is an agreement that 
problem solving is a cognitive process (Jonassen, 1997; Mayer \& Wittrock, 2006), difficult and demanding activity (Raven, 2000). Jonassen (1997) stress that problem solving "as activity is more complex than the sum of its component parts" (p.66). The complexity is emphasized by the fact that problem solving involves motivation and an emotional component (Jonassen, 1997; Dostal, 2015; Funke, Fischer, \& Holt, 2018)). Neuroscience research (Zull, 2004) supports the later issue. Emotions and thoughts are physically intertwined: particular cognitive experience is connected with particular body feeling and influence motivation. In reference to foregoing, problem solving obviously has considerable educational potential.

\section{The Models for Problem Solving Development}

From educational point of view, a problem "is understood as a difficulty of theoretical or practical nature that causes an inquiring attitude of a subject and leads him/her to the enrichment of his/her knowledge" (Kupisiewicz, 1964; as cited in Dostal, 2015, p. 2799). This definition highlights the learning through problem solving. Learning takes place by finding the space between the known and the unknown. This space is filled with acquired knowledge, skills, and experiences leading to a certain competency.

Stanic \& Kilpatrick (1988; as cited in Schoenfeld, 2016) presents several topics of how problem solving is used for teaching purposes. Although authors discussed problem solving in mathematics teaching, it is worth to pay attention, as these topics are widely used in different fields of science. The first topic indicates problem solving as context where problems are applied as the means to achieve of other curriculum goals. Teaching of problem solving is minimal, as learner performs the stated tasks. The second topic represents problems solving as skill, yet narrowly defined as "being able to obtain solutions to the problems assigned" (Schoenfeld, 2016, 5). Therefore, such skill is worth to teach in its own right. Mostly various methods of problem solving are taught within subject matter and practicing stated problems so that the methods can be mastered. These two above mentioned topics typically are used in problem-based learning and casebased learning. In contrast to the former two, the final topic emphasizes problem solving as an art where the real-life and challenging problems are employed. Undoubtedly, this topic is more reasonable for teaching and learning of problem solving.

In fact, problem solving is indicated as one of the most meaningful and important ways of learning (Jonassen, 1997). However, its education is one of the greatest challenges (Mayer \& Wittrock, 2006). Highlighting problem solving as one of the core competencies required for future professionals 


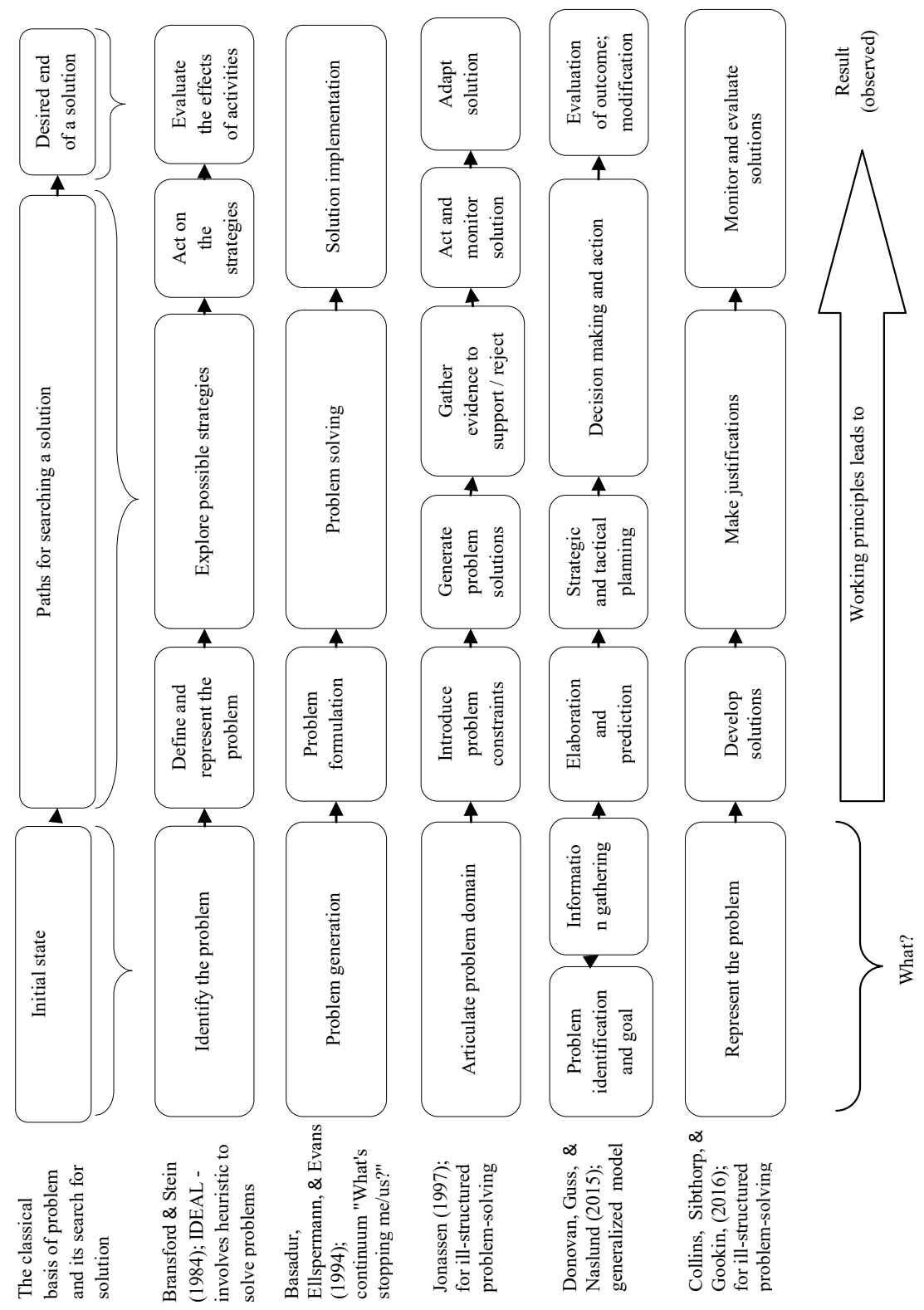

Figure 1. The steps of the problem solving process: different approaches (on the basis of Basadur, Ellspermann, \& Evans, 1994; Jonassen, 1997; Dorst, 2011; Schunk, 2012; Donovan, Guss, \& Naslund, 2015; Collins, Sibthorp, \& Gookin, 2016) 
(PISA, 2015; World Economic Forum, 2016), models for its development are sought (see Figure 1). The authority of rationality in the problem solving paradigm (Korte, 2003) clarifies likeness of the logical and even stylish structure of these models. Problem solving researchers have different representations about what is the basis for solving a problem. Although each model presents certain steps, they all share the same intention: a search for the solution from the initial state to the desired state.

Such classical approach to problem solving underlines the procedural process of problem solving and supports a rational approach. After identification of the problem, a problem solver jumps into generation of alternatives. In this case, focus is on the problem, not on its understanding and the problem itself directs the whole solving process. When the problem solver pays less attention to the analysis of the problem, its thorough understanding is limited. As a result, the problem solver could solve the wrong problem in the right way to some extent. The right way means that the problem solver employs usual way to solve problems which Dorst (2011) called deductive reasoning. The problem solver knows the "what" (an initial state) and working principals (paths searching for the solution). For this reason, the problem solver can predict results (desired end of the solution) which are often more or less convenient for the problem solver. Such problem solving process concentrates on what to think. Hence, the problem solver creates a script pattern of how to act in a similar situation. However, the similar situation is not the same one, as in each situation the context, participants, stakeholders, circumstances, factors and other features will be different. Clearly, a script pattern does not fit for all events the problem solver encounters.

Duch, Groh, \& Allen (2001) stresses that the essence of problem solving is to acquire various experiences and to create cognitive strategies that could be used in the future. What is more, learning process is significant in problem solving, not just outcomes of such learning (Duch, Groh, \& Allen, 2001; Yener, 2016). Problem solving as learning from the problem solver requires more than only possessing certain knowledge and operational skills. The insufficient development of problem solving abilities (PISA, 2015) discloses a shortage of use only the rational approach to problem solving. Thus, the emphasis should be put on how to think when solving problems. This means to learn to solve the right problem in the right way. Such an opportunity for problem solving suggests values approach.

\section{Problem solving integrating value approach}

Values integration into problem solving fosters the way of how to think. However, first is necessary to clarify one subject. Problem solving 
and decision-making are presented as separate processes. Therefore, these processes share quite similar steps. According to Huit (1992), this could explain why terms of problem solving and decision-making are sometimes used interchangeably. The unification of different processes is misleading position. Decision-making is a selection process where one from several possible solutions is chosen to reach a desired state (Huit, 1992). Meanwile, problem solving is "a process in which we perceive and resolve a gap between a present situation and a desired goal, with the path to the goal blocked by known or unknown obstacles" (Huit, 1992, 34). Indeed, decision-making is a part of problem solving.

While decision-making through ethical issues encompass values, values are like forgotten theme in problem solving. Nevertheless, values can offer reasonable reinforcement for problem solving. Researchers (Schwartz, 1992; Halstead, 1996; Verplanken \& Holland, 2002; Argandona, 2003; Roccas, Sagiv, \& Navon, 2017) claim that values guide and affect personal behavior encompassing the ethical aspects of solutions. Further is discussed how this influence manifests. According to Halstead (1996), values are principles, fundamental convictions, ideals, standards or life stances which act as general guides to behaviour or as points of reference in decision making or the evaluation of belief or action and which are closely conected to personal integrity and personal identity (p.5).

This comprehensive definition of values brightens the issue. Like others researchers (e.g. Schwartz, 1992; Argandoña, 2003), Halstead's (1996) definition highlights the influence of values on decision-making. Such the emphasis also makes clearer why decision-making models are more concerned with values than problem solving. Further, by applying values as "normative standards to judge and to chose amongst alternative modes of behaviour" (Schwartz, 1992, 2), the significance of values for alternatives and their evaluation in problem solving is revealed. Keeney (1996) considers values as the core criteria for evaluating the desirability of any alternative leading to the desired solution. Thus, values help to create worthier alternatives as well as to evaluate them. Moreover, values encompass the future consequences of the solution. When searching for a solution, the goal is necessary. As Keeney (1996) represents decisionmaking approach, he underlines that starting point for decision-making process are values primary expressed in the goals. Skimina, Cieciuch, \& Strus (2018) assert that values reflect the content of the goals. On the whole, values represent the essential foundation for problem solving and could be integrated into it by several ways (see Figure 2). 

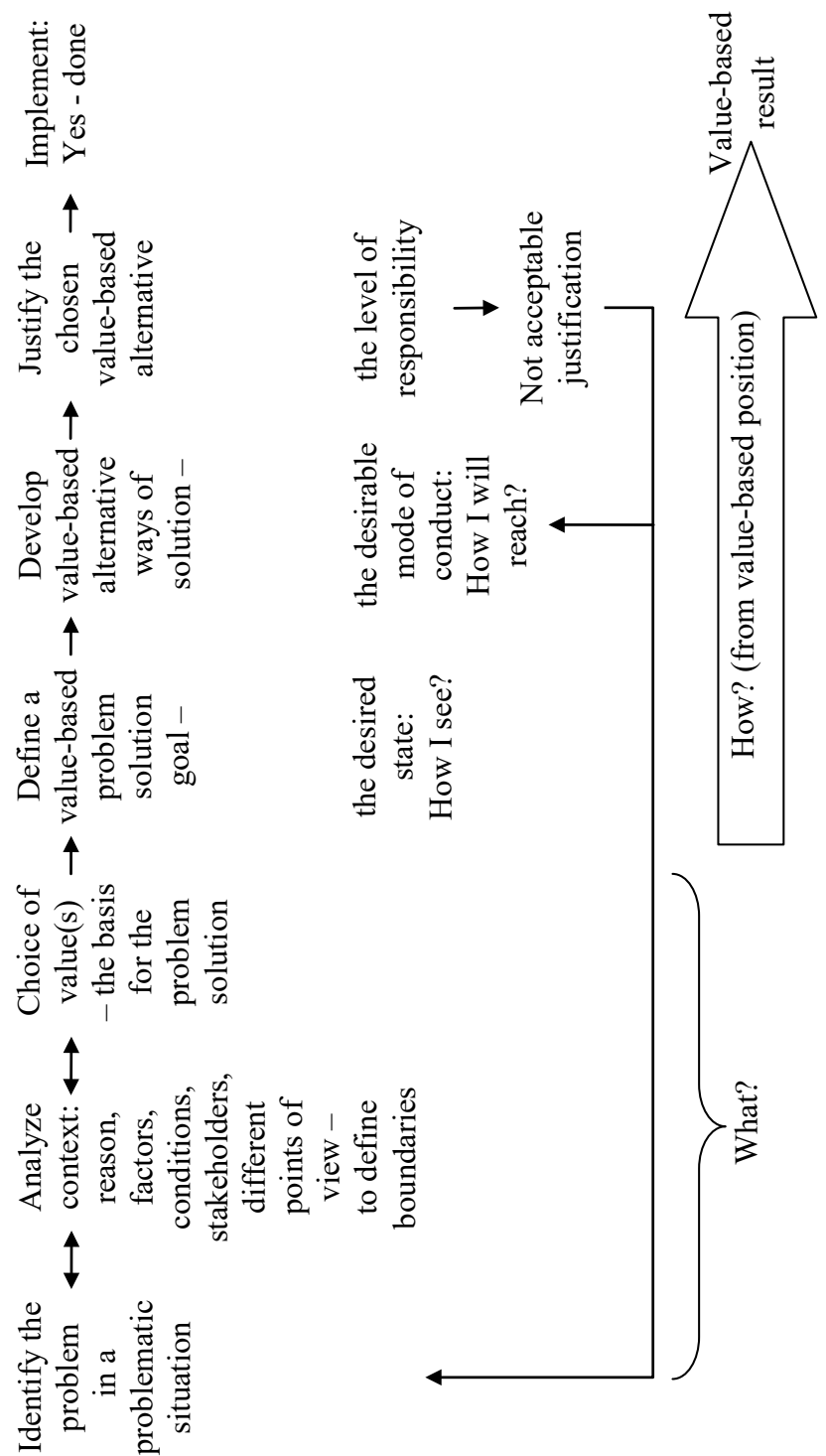

Figure 2. The framework of value-based problem solving

Based on above mentioned assumptions, the Figure 2 presents the framework of value-based problem solving process. This process integrates main steps of problem solving, decision-making and value approach. The first step encompasses the recognition of a problematic situation trying to identify where a problem is and to name it. The second step emphasis the thorough analysis of the identified problem in its context. 
These first two steps allow the problem solver to draw a comprehensive picture of the problem in pursuance to understand it. During such "conversation with the problem" (Raven, 2000, 479), the problem solver aims to clarify the nature of the problem and potential directions for a solution. Hence, the analysis of the context helps to define boundaries of attention (Hester \& MacG, 2017). These boundaries encompass values that according to Hester \& MacG (2017) are one of the salient qualities of the context and guide the attention of the problem solver into the analyzed problem. The third step requires to choose value (or several) that will help to solve the problem and guide the search of a desired solution. The goal as the desired state based on chosen value (or several) is set in the fourth step. This goal requires answer to the question "How I see the desired end of a solution?". The creation of alternative ways leading to the desired solution is in the fifth step. The established goal represents the main criteria for the creation of alternative ways. Further, created alternatives should reveal the desirable mode of conduct answering to the question "How I will reach the desired end of a solution?". The justification of the chosen alternative way is in the sixth step. As Zsolnai (2008) argues, the perceived responsibility essentially determines the choice. Thus, the chosen alternative way represents what level of responsibility the problem solver takes on when solving the problem. If justification reveals meaningful search for the desired solution in all respects (as mentioned in the analysis of context), the problem solver will proceed with its implementation. In contrast, the problem solver backs to the creation of the alternative ways for a solution, or even to the analysis of the problem. Overall, the presented process requires paying more attention to the analysis of the problem. The path for a solution becomes more complex and hardly predictable. However, values guides overall process, not the problem itself and such the process represents the shift from what to think to how to think.

\section{Discussion}

While education of certain values faces challenges with their internalization (Yazdani \& Akbarilakeh, 2017), research in value-based education (Kirschenbaum, 1992), problem-based education (Kirkman, 2017) encourage educators to help learners to identify values, to think about them and to develop higher levels of moral reasoning. Problem solving integrating values could be helpful to foster meaningful learning and to promote the development of the capabilities of problem solving and moral reasoning along with responsibility. Mastering these capabilities learners could transfer what their have learned into various situations of their professional and personal life. 
Duch, Groh, \& Allen (2001) consider problem solving as an internal psychological process. Such process during learning leads to a physical change in the brain which enables learner's self-construction process (Duch, Groh, \& Allen, 2001; Zull, 2003). The introduced value-based problem solving process fosters self-construction process of the problem solver through "four core pillars of learning" (Zull, 2003, p.). First, the problem solver gets information during analysis of the problem and its identification. Second, makes meaning of this information when choose the value (or several) and sets the goal. Further, when creates alternative ways for a solution and justify the chosen alternative, the problem solver creates new ideas from these meanings. Finally, the implementation of the chosen and justified alternative represents acting on those ideas. Moreover, such selfconstruction process forms the problem solver's character which according to Argandoña (2003), gives a consistency to subsequent decisions.

The implementation of introduced problem solving integrating values could be a challenge for educators. For teaching and learning purposes, this framework could be incorporated into curriculum. One possibility is to integrate this framework into a particular module / course of the social science curriculum. The minimal criteria for such module /course could be as follows: supports multidisciplinary approach; includes life-problems solving activities; applies flexible teaching/learning methods; fosters moral and ethical issues. The particular module / course provide changes that involve the development of theoretical aspects of problem solving and values. In order to reveal how the learners have mastered the theoretical framework, it can be verified in practice, i.e. the learners solve a problem presented by teachers or chosen by the learners themselves. Another possibility is to design a new specific module / course based on this theoretical framework. Therefore, this possibility is more challenge and requires relevant competences of the teachers.

This problem solving integrating values could serve as a teaching tool in problem-based learning and case-based learning. Trying to promote learning, several issues need to be considered. First, problem-based learning and case-based learning use prepared cases. The main weakness of these cases is that learners analyze them through the lens of a third person. According to Kirkman (2017), this is a detached point of view. To change such view, author suggests to use problem situations, which "take the focus of a second-person narrative calling for a first person respond". Moreover, problem situations contribute the creation of more than one alternative and how each alternative might be implemented referring to values. Second, problem solving as an art (Schoenfeld, 2016) should be fostered. Potentially, the whole process of problem solving integrating values could 
enable learners to learn to create the meaningful and responsible attitude to their life.

Regardless of that, the complexity of problem solving integrating values represents its limitation. This process is long enough and requires learners' effort, time, and motivation. To take advantage of these resources is worth as Kirkman's (2017) findings show that becomes "impossible not to attend to values" in various situations when a person learned to think about and noticed them.

\section{Conclusions}

From the perspective of education, problem solving integrating values provides the problem solver with a tool that enables the development of value-based problem solving capability. While the introduced framework consists of six steps, distinct capabilities are developed in each step. The problem solver is enabled to develop the perception of the problematic situation and to identify the problem (the first step) as well as to make a thorough analysis of the context where problem emerged (the second step). Problem solver develops a capability to choose a value as the background for the solution (the third step) and to formulate the value-based goal of the solution as the desired result (the fourth step). During the fifth step the problem solver develops the capability to create value-based alternatives highlighting a process which reveals how to search the solution. Finally, problem solver learns to make sound justification which is the rationale for problem solution (the sixth step). Moreover, during value-based problem solving process the problem solver bases his values twice (first time in the third step when defines a desired state and second time in the fourth step when decides on the desirable mode of conduct).

Future research could cover the verification of the introduced framework for problem solving integrating values. First possibility is concerned with incorporation of this framework into curriculum. The creation of educational environments for the development of value-based problem solving capability is encouraged seeking meaningful incorporation. Second, it could be reasonable to use this framework as innovative activity which fosters learning and the development of variety capabilities, for example, during problem-based learning and case-based learning.

Given the fact that problem solving is expected to be incorporated into every curriculum, to foster the practice of problem solving which integrates values is necessary. Especially if we find agreeable that the young generation should and could have a thorough approach how worthwhile to solve problems and to reason from values point of view. 


\section{References}

Argandoña, A. (2003). Fostering values in organizations. Journal of Business Ethics, 45(1-2), 15-28. Retrieved from https://link.springer.com/content/pdf/10.1023/ A:1024164210743.pdf.

Barnett, R. (2014). Thinking about higher education. In Thinking about higher education (pp. 9-22). Springer International Publishing.

Basadur, M., Ellspermann, S. J., \& Evans, G. W. (1994). A new methodology for formulating ill-structured problems. Omega, 22(6), 627-645.

Beghetto, R. A. (2016). Leveraging Micro-Opportunities to Address Macroproblems. In Creative Intelligence in the $21^{\text {st }}$ Century (pp. 159-174). SensePublishers, Rotterdam.

Binkley, M., Erstad, O., Herman, J., Raizen, S., Ripley, M., Miller-Ricci, M., \& Rumble, M. (2012). Defining twenty-first century skills. In Assessment and teaching of $21^{\text {st }}$ century skills (pp. 17-66). Heidelberg: Springer.

Cho, Y. H., Caleon, I. S., \& Kapur, M. (Eds.) (2015). Authentic problem solving and learning in the $21^{\text {st }}$ century: Perspectives from Singapore and beyond. Singapore: Springer.

Collins, R. H., Sibthorp, J., \& Gookin, J. (2016). Developing ill-structured problemsolving skills through wilderness education. Journal of Experiential Education, 39(2), 179-195. Retrieved from https://doi.org/10.1177/1053825916639611.

Csapo, B., and Funke, J. (2017). The development and assessment of problem solving

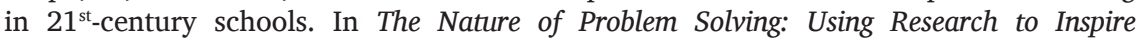
$21^{\text {st }}$ Century Learning, eds B. Csapó and J. Funke (Paris: OECD Publishing), 19-31, (Chapter 1).

Donovan, S. J., Guss, C. D., \& Naslund, D. (2015). Improving dynamic decision making through training and self-reflection. Judgment and Decision Making, 10(4), 284-295. Retrieved from https://digitalcommons.unf.edu/apsy_facpub/2.

Dorst, K. (2011). The core of 'design thinking'and its application. Design studies, 32(6), 521-532. Retrieved from https://doi.org/10.1016/j.destud.2011.07.006.

Dostál, J. (2015). Theory of problem solving. Procedia-Social and Behavioral Sciences, 174(1), 2798-2805. Retrieved from https://doi.org/10.1016/j.sbspro.2015.01.970.

Duch, B. J., Groh, S. E., \& Allen, D. E. (2001). The power of problem-based learning: a practical" how to" for teaching undergraduate courses in any discipline. Stylus Publishing, LLC.

Ellspermann, S. J., Evans, G. W., \& Basadur, M. (2007). The impact of training on the formulation of ill-structured problems. Omega, 35(2), 221-236. Retrieved from https://doi.org/10.1016/j.omega.2005.05.005.

Euler, D., \& Kühner, P. (2017). Problem-Based Assignments as a Trigger for Developing Ethical and Reflective Competencies. Interdisciplinary Journal of Problem-Based Learning, 11(2), 2. Retrieved from https://doi.org/10.7771/1541-5015.1668.

Fischer, A., \& Neubert, J. C. (2015). The multiple faces of complex problems: a model of problem solving competency and its implications for training and assessment. Journal of Dynamic Decision Making, 1(1), 1-13. Retrieved from https://doi.org/10.11588/ jddm.2015.1.23945.

Funke, J., Fischer, A., \& Holt, D. V. (2018). Competencies for complexity: problem solving in the twenty-first century. In Assessment and teaching of $21^{\text {st }}$ century skills (pp. 41-53). Springer, Cham. 
Grant, M. J., \& Booth, A. (2009). A typology of reviews: an analysis of 14 review types and associated methodologies. Health Information \& Libraries Journal, 26(2), 91-108. Retrieved from https://doi.org/10.1111/j.1471-1842.2009.00848.x.

Hall, D. J., \& Davis, R. A. (2007). Engaging multiple perspectives: A value-based decision-making model. Decision Support Systems, 43(4), 1588-1604. Retrieved from https://doi.org/10.1016/j.dss.2006.03.004.

Halstead, J. M. (1996). Values and values education in schools. In J. M. Halstead, M. J. Taylor (Eds.) Values in education and education in values (pp. 3-14), London: The Falmer Press.

Harland, T., \& Pickering, N. (2010). Values in higher education teaching. Routledge.

Herde, C. N., Wustenberg, S., \& Greiff, S. (2016). Assessment of Complex Problem Solving: What We Know and What We Don't Know. Applied Measurement in Education, 29(4), 265-277. doi: 10.1080/08957347.2016.1209208.

Hester, P. T., \& MacG, K. (2017). Systemic decision making: fundamentals for addressing problems and messes. Cham: Springer.

Huitt, W. (1992). Problem solving and decision making: Consideration of individual differences using the Myers-Briggs Type Indicator. Journal of Psychological type, 24(1), 33-44. Retrieved from http://citeseerx.ist.psu.edu/viewdoc/download?doi=10.1.1.643 $.3379 \&$ rep $=$ rep $1 \&$ type $=$ pdf.

Yazdani, S., \& Akbarilakeh, M. (2017). The Model of Value-Based Curriculum for Medicine and Surgery Education in Iran. Journal of Minimally Invasive Surgical Sciences, 6(3). doi: 10.5812/minsurgery.14053.

Jonassen, D. H. (1997). Instructional design models for well-structured and III-structured problem-solving learning outcomes. Educational Technology Research and Development, 45(1), 65-94. Retrieved from https://link.springer.com/content/ pdf/10.1007\%2FBF02299613.pdf.

Jonassen, D. H. (2011). Learning to solve problems: A handbook for designing problemsolving learning environments. NY and London: Routledge.

Keeney, R. L. (1994). Creativity in decision making with value-focused thinking. MIT Sloan Management Review, 35(4), 33-41.

Kirkman, R. (2017). Problem-based learning in engineering ethics courses. Interdisciplinary Journal of Problem-Based Learning, 11(1), 4. Retrieved from https://doi. org/10.7771/1541-5015.1610.

Kirschenbaum, H. (1992). A comprehensive model for values education and moral education. The Phi Delta Kappan, 73(10), 771-776.

Korte, R. F. (2003). Biases in decision making and implications for human resource development. Advances in Developing Human Resources, 5(4), 440-457.

Mayer, R. E., \& Wittrock, M. C. (2006). Problem-solving. Handbook of educational psychology, 2, 287-303. Retrieved from https://doi.org/10.1177/1523422303257287.

Yener, Ö. Z. E. N. (2016). Can I solve the problem? A program trail on problem solving skill. American Journal of Applied Psychology, 4(1), 1-10. doi: 10.12691/ajap-4-1-1.

Ozolinšs, J. J. T. (2015). Reclaiming Paedeia in an Age of Crises: Education and the necessity of wisdom. Educational Philosophy and Theory, 47(9), 870-882. https://doi. org/10.1080/00131857.2015.1035154. 
PISA. (2015). PISA: Results in Focus. Organisation for Economic Co-operation and Development: OECD. Retrieved from https://www.oecd.org/pisa/pisa-2015-results-infocus.pdf.

Raven, J. (2000). Psychometrics, cognitive ability, and occupational performance. Review of Psychology, 7(1-2), 51-74. Retrieved from http://mjesec.ffzg.hr/revija.psi/ vol\%2007\%20no\%201-2\%202000/Raven_2000-7-1-2.pdf.

Roccas, S., Sagiv, L., \& Navon, M. (2017). Methodological issues in studying personal values. In Values and Behavior (pp. 15-50). Springer, Cham. Retrieved from https://doi. org/10.1007/978-3-319-56352-7_2.

Salgado, F. P., Abbott, D., \& Wilson, G. (2018). Dimensions of professional competences for interventions towards sustainability. Sustainability science, 13(1), 163-177. Retrieved from https://doi.org/10.1007/s11625-017-0439-z.

Schoenfeld, A. H. (2016). Learning to think mathematically: Problem solving, metacognition, and sense making in mathematics (Reprint). Journal of Education, 196(2), 1-38. Retrieved from https://journals.sagepub.com/doi/pdf/10.1177/ 002205741619600202.

Schunk, D. H. (2012). Learning theories an educational perspective (6 ${ }^{\text {th }}$ ed.). Pearson.

Schwartz, S. H. (1992). Universals in the content and structure of values: Theoretical advances and empirical tests in 20 countries. In Advances in experimental social psychology (Vol. 25, pp. 1-65). Academic Press. doi:10.1016/S0065-2601(08)60281-6.

Skimina, E., Cieciuch, J., \& Strus, W. (2018). Traits and values as predictors of the frequency of everyday behavior: Comparison between models and levels. Current Psychology, 1-21. Retrieved from https://doi.org/10.1007/s12144-018-9892-9.

Sternberg, R. J. (2017). Speculations on the role of successful intelligence in solving contemporary world problems. Journal of Intelligence, 6(1), 1-10. doi: 10.3390/ jintelligence6010004.

Sternberg, R. J. (2009, July). We need to teach for ethical conduct. In The Educational Forum (Vol. 73, No. 3, pp. 190-198). Taylor \& Francis Group. doi: $10.1080 / 00131720902991228$.

Thornton, M. (2004). The idea of the university and the contemporary legal academy. Sydney Law Review, 26(4), 481-502.

Verplanken, B., \& Holland, R. W. (2002). Motivated decision making: Effects of activation and self-centrality of values on choices and behavior. Journal of personality and social psychology, 82(3), 434-447. Retrieved from http://dx.doi. org/10.1037/0022-3514.82.3.434.

Wood, C. (2006). The development of creative problem solving in chemistry. Chemistry Education Research and Practice, 7(2), 96-113. doi: 10.1039/B6RP90003H.

World Economic Forum. (2016, March). New vision for education: Fostering social and emotional learning through technology. Geneva, Switzerland: World Economic Forum. Retrieved from http://www3.weforum.org/docs/WEF_New_Vision_for_Education.pdf.

Zsolnai, L. (2008). Responsible Decision Making. New Brunswick and London: Transaction Publishers.

Zull, J. E. (2004). The art of changing the brain. Educational Leadership, 62(1), 68-72. Retrieved from http://citeseerx.ist.psu.edu/viewdoc/download?doi $=10.1 .1 .504 .5667 \&$ rep $=$ rep $1 \&$ type $=$ pdf. 